\title{
The Importance of Mental Health Courts for Psychiatry \& the Criminal Justice System
}

\author{
Alexander Simmons \\ University of Ottawa, Faculty of Medicine, Ottawa, Ontario, Canada
}

ABSTRACT

Mental health courts (MHCs) are designed to divert offenders with mental illness away from the criminal justice system and into appropriate treatment programs. This commentary highlights the systemic issues within the healthcare system that led to the development of MHCs. Research has already demonstrated that these courts are associated with numerous positive psychiatric and legal outcomes. However, further research is required to determine what specifically makes them successful, and who is most likely to benefit from them. MHCs have earned their place as an essential part of the criminal justice system and are a promising area of future research.

\section{RÉSUMÉ}

Les tribunaux de santé mentale sont conçus pour détourner les criminels atteints de maladie mentale du système de justice criminel et de les orienter vers les programmes de traitement appropriés. Cette critique met en évidence les problèmes systémiques du système de santé qui ont conduit au développement de ces tribunaux de santé mentale. De nombreuses études ont déjà démontré que ces tribunaux sont associés à de nombreux résultats psychiatriques et juridiques positifs. Cependant, de la recherche supplémentaire est nécessaire afin de déterminer ce qui les rend particulièrement fructueux et identifier ceux qui en bénéficieraient le plus. Les tribunaux de santé mentale ont acquis une place essentielle dans le système de justice criminel et constituent un domaine de recherche prometteur dans le futur.

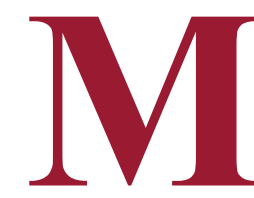

ental health courts (MHCs) aim to address the needs of those with mental illness entering the criminal justice system by providing access to appropriate services and facilitating diversion when possible. They are based on the successful model of drug courts, in which individuals with substance use disorders are placed into treatment programs (1). These courts vary widely in terms of their function but share the common mandate of rehabilitating those who would be otherwise criminally sanctioned (1).

In Ontario, there are nineteen MHCs in operation, and the provincial Human Services \& Justice Coordinating Committee has identified a need for more resources dedicated to MHCs (34). This is, in part, due to the significant increase in the number of hospital beds and other resources dedicated to the forensic population in Ontario (2). Criminally accused individuals often end up in forensic institutions as a result of being found unfit to stand trial (UST) or following a verdict of not criminally responsible on account of a mental disorder (NCRMD) $(3,4)$. Those found UST may then receive a fitness treatment order, which requires them to receive psychiatric treatment in order to be rendered fit. Those found NCRMD are followed by review boards, independent tribunals, that determine the disposition of the accused person (5). The dispositions available include detention in hospital, conditional discharge (typically living in the community under conditions set by the review board), or absolute discharge (5). Accused persons are typically required to participate in individually tailored treatment programs developed by multi-disciplinary healthcare teams (1). There has been an overall national increase in the number of people found NCRMD in Canada (3). The rapid proliferation of MHCs since their establishment in the late 1990s has helped to facilitate this process (6). MHCs are associated with numerous positive outcomes; however, further research regarding their efficacy is required in order to inform public policy.

\section{THE NEED FOR MHCs}

Since the deinstitutionalization movement in the second half of the twentieth century, access to mental health services has become increasingly scarce (1). As a result, those with mental illness have often ended up in the forensic system, and the responsibility of providing basic mental healthcare has largely shifted to the criminal justice system (7). A recent study of mental illness in jails found that $14.5 \%$ of men and $31 \%$ of women had a serious mental illness (9). These individuals often do not have access to mental health services while incarcerated, which may lead to worse long-term outcomes.

Keywords: Mental Health Court; Psychiatry; Mental Illness; Criminal Justice System; Forensic 
The shift of those with mental illness into the forensic system has been referred to as the criminalization of mental illness; fortunately, MHCs pose a potential solution. MHCs can help shift those with severe mental illness from the prison system into a court-mandated treatment program. This provides an opportunity for offenders with mental illness to access psychiatric treatment, which they may have been previously lacking. MHC diversion also provides an opportunity for lessened sentences or the withdrawal of charges reliant on the accused participating in mental health treatment. There is increasing demand being placed on forensic institutions to provide mental health services due to inadequate resources elsewhere. Individuals with mental illness who are found UST often must wait in jail, without access to psychiatric care, until they can be admitted to hospital (7). An increase in the number of MHCs could help facilitate the diversion process and reduce demand on the already overwhelmed criminal justice system.

\section{THE EFFICACY OF MHCS}

Since their inception, research has rapidly accumulated demonstrating the efficacy of MHCs. One major advantage of MHCs is their ability to link individuals to mental health services (10). One MHC in Florida reported linking up to $82 \%$ of its participants with mental health treatment (11). At eight months follow up, MHC participants engaged in a higher level of treatment when compared to individuals in the traditional misdemeanor court (11). MHCs therefore play an important role in making mental healthcare more accessible to those who need it most.

A growing body of research has also shown that MHCs are effective in reducing recidivism (the tendency of a convicted criminal to reoffend) $(10,32)$. Across four diverse MHCs, participants were shown to have significantly fewer re-arrests and incarceration days compared to those in a standard treatment group (12). MHCs are therefore capable of achieving important public safety outcomes in a cost-effective manner. One study estimates that a Pennsylvania MHC saved taxpayers three and a half million dollars over a two-year period (13). This cost saving was achieved by cutting down on more expensive forms of treatment, such as hospitalization (13).

By focusing on rehabilitation rather than punishment, MHCs are also leading to subjective improvements in the quality of life of those with severe mental illness (10). MHC participants and graduates have a significant reduction in psychiatric hospitalization days and a decrease in positive drug and alcohol tests over the course of court enrollment (14). This suggests that MHCs may lead to benefits beyond the evident positive legal outcomes. A recent study found that $91 \%$ of MHC clients could cite advantages to their participation in the court program (15). These advantages are often attributed to the fact that MHCs treat participants not as criminals but as individuals who engaged in criminal activity as a result of severe mental illness. MHCs are unique in that they operate generally under the principle of therapeutic jurisprudence (28). Therapeutic jurisprudence refers to the belief that laws can be helpful or unhelpful to defendants, and sometimes even harmful (29). Direct interaction between the accused and the judge during courtroom sessions is another distinguishing feature of MHCs (14). Judges in MHCs often receive additional mental health training and are in an optimal position to establish a therapeutic alliance with the accused (16). Observations reveal a non-adversarial tone in the courtroom in which the use of praise and encouragement far outweigh sanctions (14). The unique rehabilitative focus of MHCs may facilitate some of their positive outcomes. MHC participants have reported that their motivation initially was to avoid jail, but over time they began to make intentional choices leading to their recovery (17). They cited the importance of their relationship with the staff and the judge, as well as the need for trust, understanding and respect throughout the program $(17,33)$. The growing body of evidence supporting the efficacy of MCHs cements them as an important part of the forensic system. However, further research is required to determine what specific features make them successful, and who is most likely to benefit from them.

\section{LIMITATIONS OF MHCS}

Despite the many positive outcomes associated with MHCs, there remain some limitations. One major disadvantage of MHCs is that they are reactionary in nature (10). Treatment is only offered to offenders with mental illness after they have committed a crime, rather than intervening before they become involved with the criminal justice system (10). MHCs therefore serve as a solution to a larger problem rooted in the existing deficiency of mental health resources. This issue could be mitigated by increased funding for diversion of offenders with mental illness prior to being charged (e.g. police education) in order to reduce the need for MHCs (34).

Another concern with respect to MHCs is whether participants are joining voluntarily, or if coercion is taking place (10). A recent study found that the majority of participants had agreed to participate in the MHC yet claimed to have not been 
told that the program is voluntary (18). Another potential legal concern is related to pleading guilty (10). To participate in a MHC, the defendant typically has to plead guilty under the assumption that charges will be dismissed once treatment has been completed (19). The Bazelon Center performed a review of $20 \mathrm{MHCs}$ and found that the charges were not always automatically dismissed, despite defendants' participation in treatment (19).

An additional disadvantage of MHCs is the potential for gender and race bias in those selected as participants (10). Existing literature suggests that Caucasian males, and in some cases, Caucasian females are over-represented in MHCs (21). Further research is required to understand how MHC participants are selected, in order to avoid such bias.

An overarching limitation of MHCs is the lack of consistency amongst them. The variability amongst MHCs is largely attributed to a lack of regulation at the provincial level. In Ontario, there is no mandate to determine where they should exist, and how they should operate (34). They are therefore quite variable and lack a uniform framework to guide their function. There is also a relative lack of peer-reviewed studies demonstrating what specific features make them successful (10). A lack of dedicated funding and a lack of psychiatrists have been reported as the primary challenges faced by MHCs across Ontario (34). Therefore, an increase in provincial funding and further research into how MHCs can operate most effectively is required.

\section{FUTURE DIRECTIONS}

MHCs represent an innovative solution that addresses the needs of offenders with mental illness that are not being met elsewhere. They are a successful, permanent component of the criminal justice system with documented results and should no longer be funded as 'pilot projects' (23). It is clear that MHCs lead to positive outcomes; however, the causal mechanism underlying these outcomes is not well understood. It could be the participants' interaction with the judge during MHC sessions that is contributing to positive outcomes, as is the case in the drug courts $(20,24,25)$. However, it could also be the mental health services received, amount of court supervision, sanctions for non-compliance or some combination of the above (14). Despite their variability, all MHCs in Ontario report an interest in providing clients with access to mental health services (34). This underlying commonality could likely be the source of their success. There is a need for further research into this topic, in order to develop a theoretical framework to guide MHC function.

There is also a need for investigation into who is most likely to benefit from MHC involvement, and under what circumstances (1). This is especially true given the increasing heterogeneity of MHC participants, in both criminal behavior and clinical profile (5). This could lead to more effective selection of participants in order to maximize positive outcomes. An important eligibility criterion required by almost all MHCs in Ontario is a willingness to participate and be treated if necessary (34). The National Institute for Health \& Care Excellence recommends that the nature and severity of the mental health problem also be taken into account, as well as any co-existing substance use disorders (35).

It is evident that MHCs are a promising intervention with abundant potential for future research. Methodologicallysound single- and multi-site studies on MHC participants, available treatment services, community characteristics, criminal justice, psychosocial outcomes and cost-effectiveness are required to identify for whom MHCs are truly successful and why $(26,27,30)$.

\section{CONCLUSIONS}

MHCs have proliferated rapidly since they began in the late 1990s. They have proven to be an effective solution to stop the revolving door of those with severe mental illness through the criminal justice system. Evidence has shown that they are able to address the unique needs of these individuals and lead to long-term positive outcomes, in a cost-effective manner. More work needs to be done to identify exactly what makes MHCs so successful and who is most likely to benefit. So far research has not been able to keep pace with their rapid growth, and there is yet to be a comprehensive examination of more than a few MHCs (31). Existing MHCs are quite variable in their function due to the lack of a guiding theoretical framework. They are also reactionary in nature and do not address the factors that are leading mentally ill individuals to become involved with the criminal justice system in the first place. Despite their limitations, MHCs have earned their place as an essential part of the criminal justice system and are a promising area of future research.

\section{REFERENCES}

1. Schneider, RD. Mental health courts. Current Opinion in Psychiatry. 2008;21:510-513.

2. Seto, MC, Lalumière, ML, Harris, GT, et al. Demands on forensic mental 
health services in the province of Ontario. Toronto (ON): Report prepared for the Ontario Ministry of Health and Long-Term Care. 2001.

3. Latimer, J, Lawrence, A. The review board systems in Canada: overview of results from the Mentally Disordered Accused Data Collection Study. Ottawa (ON): Department of Justice Canada. 2006.

4. Schneider, RD, Forestell, M, MacGarvie, S. Statistical survey of provincial and territorial review boards. Ottawa (ON): Department of Justice Canada. 2002.

5. Crocker, AG, Nicholls, TL, Seto, MC, Cote, G, Charette, Y, Caulet, M. The national trajectory project of individuals found not criminally responsible on account of a mental disorder in Canada, Part 1: Context and methods Canadian Journal of Psychiatry. 2015;60(3):98-105.

6. Moore, ME, Hiday, VA. Mental health court outcomes: a comparison of rearrest and re-arrest severity between mental health court and traditional court participants. Law \& Human Behavior. 2006;30:659-674.

7. Wortzel, H, Binswanger, IA, Martinez, R, Filley, CM, Anderson, CA. Crisis in the treatment of incompetence to proceed to trial: harbinger of a systemic illness. The Journal of the American Academy of Psychiatry and the Law. 2007;35:357-363.

8. Schneider, RD. A statistical survey of provincial and territorial review boards. Ottawa (ON): Federal Department of Justice. 2000.

9. Steadman, HJ, Osher, FC, Clark Robbins, P, Case, B, Samuels, S. Prevalence of serious mental illness among jail inmates. Psychiatric Services. 2009;60:761-765.

10. Sarteschi, CM, Vaughn, MG, Kim, K. Assessing the effectiveness of mental health courts: A quantitative review. Journal of Criminal Justice. 2011;39:12-20.

11. Boothroyd, R, Poythress, N, McGaha, A, Petrila, J. The Broward Mental Health Court: Process, outcomes and service utilization. International Journal of Law and Psychiatry. 2003;26:55-71.

12. Steadman, HJ, Redlich, A, Callahan, L, Robbins, PC, Vesselinov, R. Effect of mental health courts on arrests and jail days. Archives of General Psychiatry. 68(2):167-172.

13. Kaplan, A. Mental health courts reduce incarceration, save money. Psychiatric News. 2007;24.

14. Frailing, K. How mental health courts function: Outcomes and observations. International Journal of Law \& Psychiatry. 2010;33:207-213.

15. Redlich, AD, Hoover, S, Summers, A, Steadman, HJ. Enrollment in mental health courts: Voluntariness, knowingness, and adjudicative competence. Law and Human Behavior. 2010;34:91-104.

16. Edgely, M. Why do mental health courts work? A confluence of treatment, support and adroit judicial supervision. International Journal of Law \& Psychiatry. 2014;32:572-580.

17. Eschbach, LA, Dalgin, RS, Pantucci, E. A three stage model for mental health treatment court: a qualitative analysis of graduates' perspectives. Community Mental Health Journal. 2018.

18. Redlich, AD, Hoover, S, Summers, A, Steadman, HJ. Enrollment in mental health courts: Voluntariness, knowingness, and adjudicative competence. Law \& Human Behavior. 2010;34:91-104.

19. Bazelon Center for Mental Health Law. The role of mental health courts in system reform. 2004.

20. Kuehn, BM. Mental health courts show promise. JAMA. 2007;297(15):16411643.

21. Steadman, HJ, Redlich, AD. Final report: An evaluation of the Bureau of Justice Assistance Mental Health Court Initiative. Washington (DC): National Institute of Justice (NIJ). 2006.

22. Erickson, SK, Campbell, A, Lamberti, JS. Variations in mental health courts: challenges, opportunities and a call for caution. Community Mental Health Journal. 2006;42(4):335-344.

23. Acquaviva, GL. Mental health courts: no longer experimental. Seaton Hall Law Review. 2006;36:971-1013.

24. Senjo, SR, Leip, LA. Testing and developing theory in drug court: A fourpart Logit model to predict program completion. Criminal Justice Policy Review. 2001;12(1):66-87.

25. Senjo, SR, Leip, LA. Testing therapeutic jurisprudence theory: An empirical assessment of the drug court process. Western Criminology Review.
2001;3(1):1-26.

26. Steadman, HJ, Redlich, AD, Griffin, P, Petrila, J, Monahan, J. From referral to disposition: Case processing in seven mental health courts. Behavioral Sciences \& the Law. 2005;23(2):215-226.

27. Wolff, N, Pogorzelski, W. Measuring the effectiveness of mental health courts: Challenges and recommendations. Psychology, Public Policy and Law. 2005;11(4):539-569.

28. Rottman, D, \& Casey, P. Therapeutic jurisprudence and the emergence of problem-solving courts. National Institute of Justice Journal. 1999;240:12-19.

29. Winick, BJ, Wexler, DB. Judging in a therapeutic key: Therapeutic jurisprudence and the courts. The Journal of Legal Medicine. 2004;25:377388.

30. Landess, J, Holoyda, B. Mental health courts and forensic assertive community treatment teams as correctional diversion programs. Behavioral Sciences \& The Law. 2017;35:501-511.

31. Redlich, AD, Steadman, HJ, Monahan, J, Robbins, PC, Petrila, J. Patterns of practice in mental health courts: A national survey. Law \& Human Behavior. 2006;30:347-362.

32. Bonefine, N, Ritter, C, Teller, J, Munetz, MR. A comparison of participants in two community-based programs: Assisted outpatient treatment and a mental health court. Psychiatric Services. 2018;69(9):1001-1006.

33. Canada, KE, Watson, AC. "Cause everybody likes to be treated good": perceptions of procedural justice amongst mental health court participants. American Behavioral Scientist. 2013;57(2):209-230.

34. Human Services \& Justice Coordinating Committee, Canadian Mental Health Association. Mental Health Courts in Ontario: A Review of the Initiation and Operation of Mental Health Courts Across the Province. 2017.

35. Wells, C, Ford, C, Felipe, E. Mental health courts and diversion programs: guidelines. Ottawa (ON): CADTH rapid response report. 2017. 